\title{
THE PECULARITIES OF CORRELATION BETWEEN INSULIN RESISTANCE, CARBOHYDRATE AND LIPID METABOLISM INDICES IN PATIENTS WITH GRAVES'DISEASE
}

\author{
Orysia Lishchuk \\ Department of Endocrinology \\ Lviv Danylo Halytsky National Medical University \\ 69 Pekarska str., Lviv, Ukraine, 79010 \\ orusja55@ukr.net \\ Olesya Kikhtyak \\ Department of Endocrinology \\ Lviv Danylo Halytsky National Medical University \\ 69 Pekarska str., Lviv, Ukraine, 79010 \\ olesya66k@gmail.com \\ Khrystyna Moskva \\ Department of Endocrinology \\ Lviv Danylo Halytsky National Medical University \\ 69 Pekarska str., Lviv, Ukraine, 79010 \\ xuctia@hotmail.com
}

\begin{abstract}
Aim. The number of patients with endocrine disorders in the world, in particular, Graves' disease is continuously increasing. Recent studies have determined the fact of insulin resistance in thyroid disorders. On the one hand, numerous researches prove correlation of hypothyroidism with arterial hypertension, ischaemic heart disease and lipid metabolism disorder, on the other - carbohydrate metabolism disorder and hyper-sympathicotonia are closely associated with hyperthyroidism. The subject of the research was to study the correlation of insulin resistance, lipid and carbohydrate metabolism indices in patients with Graves'disease.

Material and Methods. During the study 53 (37 female and 16 male) patients with Graves' disease with noticed IR have been examined. At the beginning, after 3-and 6-months thyreostatic therapy with insulin sensitizers (metformin or pioglitazone) the following investigations have been performed: assessing thyroid-stimulating hormone levels, free thyroxine and triiodothyronine; assessing glycated haemoglobin, glucose, C-peptide and fasting insulin as primary IR markers; calculating HOMA-IR index for analysing tissue sensitivity to insulin; calculating HOMA- $\beta$ index for evaluating the functional capacity of $\beta$-cells of islets of Langerhans; measuring Caro indices to monitor hyperinsulinemia, measuring total cholesterol level, low-density lipoproteins, very-low-density lipoproteins, high-density lipoproteins, triglycerides, for analysing IR in relation to lipid metabolism.

Results. The research results found out that free thyroid hormones and thyroid-stimulating hormone are closely related to lipid metabolism. Thus, thyroid-stimulating hormone was characterized as having direct correlation with low-density lipoproteins, while the free thyroxine inversely correlated with total cholesterol, low-density lipoproteins, and high-density lipoproteins. The free triiodothyronine negatively correlated with high-density lipoproteins. The research has also determined the direct correlation between insulin and free thyroxine, as well as free triiodothyronine in patients with diffuse toxic goitre.

Conclusions. The study proves the presence of insulin resistance in patients with Graves' disease that generates interest to further study of the changes in insulin sensitivity, relation of insulin resistance to thyroid-stimulating hormone, thyroid hormones and looking for the ways to correct these disorders.
\end{abstract}

Keywords: Graves' disease, insulin resistance, correlation.

\section{Introduction}

The number of patients with endocrine disorders in the world, in particular, Graves' disease is continuously increasing [1,2]. For the last 5 years, the incidence of endocrine disorders in Ukraine has increased by $13 \%$ and the number of patients registered with thyrotoxicosis annually increases by $5 \%$, which is significantly higher than the world and European indices [3]. 
H. P. Hirnsworth and R. B. Kerr were the first to use the term "insulin resistance" in 1939. By "insulin resistance" (IR) we traditionally mean the altered tissue response to endogenous insulin, that is manifested by impaired glucose uptake in the adipose tissue and skeletal muscles, as well as suppression of hepatic gluconeogenesis [4]. Recent studies show that we can recognize IR not only in the pathogenesis of type 2 diabetes mellitus but also in many other pathological conditions, such as polycystic ovary syndrome, arterial hypertension, atherosclerosis, non-alcoholic steatohepatitis, etc. Thus, we can also observe the insulin resistance in thyroid disorders. On the one hand, numerous researches prove the correlation of hypothyroidism with arterial hypertension, ischaemic heart disease and lipid metabolism disorder, on the other - carbohydrate metabolism disorder and hyper-sympathicotonia are closely associated with hyperthyroidism [5].

Clinical and experimental studies have found out that in thyrotoxicosis insulin interacts differently with its target tissues (liver, muscles, adipose tissue, and endothelium) [6-8]. In particular, it has been found out that the frequency and degree in glucose intolerance like $\beta$-cells of the islets of Langerhans dysfunction highly depended on the severity of the clinical course of Graves'disease [9].

In Graves' disease there develops hepatic insulin resistance, accompanied by the increased fasting plasma glucose, increased endogenous glucose production by the liver due to the increased availability of gluconeogenesis precursors and glycogenolysis activation [10]. Several researchers pointed out that both thyroxine and insulin stimulate the expression of hexokinase and glycogen synthetase, which are responsible for the glucose absorption and disposal by the formation of glucose 6-phosphate and glucose-1 phosphate $[11,12]$. Researches at the molecular level revealed that most of the rat liver enzymes, involved in gluconeogenesis are regulated by thyroid hormones [13].

The influence of thyroid hormones on glucose regulation is associated with the changes in insulin secretion and hormone antagonists of insulin, glucose absorption in the intestine and its utilization by adipose and muscle tissues, stimulation of gluconeogenesis in the liver $[14,15]$. There are evidences that triiodothyronine is able to enhance glucose metabolism in the liver by the action on the hypothalamic and pituitary system. This effect is realized through sympathetic fibers involved in innervation of hepatocytes and does not depend on the level of thyroid hormones, insulin and corticosteroid content in the blood [16].

\section{Aim of the research}

To find out the correlation between insulin resistance, carbohydrate and lipid metabolism indices in patients with Graves' disease.

\section{Materials and methods}

During the study 53 (37 female and 16 male) 42,0 0 ,9 years, patients with Graves'disease with noticed IR have been examined. At the beginning, after 3-and 6-months thyreostatic therapy with insulin sensitizers (metformin or pioglitazone) the following investigations have been performed: assessing thyroid-stimulating hormone levels $(\mathrm{TSH})$, free thyroxine $\left(\mathrm{F} T_{4}\right)$ and triiodothyronine ( $\mathrm{FT}_{3}$ ); assessing glycated haemoglobin (HbAlc), glucose, C-peptide and fasting insulin as primary IR markers; calculating HOMA-IR index for analysing tissue sensitivity to insulin; calculating HOMA- $\beta$ index for evaluating the functional capacity of $\beta$-cells of islets of Langerhans; measuring Caro indices to monitor hyperinsulinemia, measuring total cholesterol level, low-density lipoproteins (LDL), very-low-density lipoproteins (VLDL), high-density lipoproteins (HDL), triglycerides (TG), for analysing IR in relation to lipid metabolism.

Functional condition of thyroid was evaluated by determining the basal serum concentrations of $\mathrm{TSH}_{2} \mathrm{FT}_{4}$ and $\mathrm{FT}_{3}$ of patients, using enzyme-linked immunosorbent assay (ELIZA) with the help of test-system of company Roche Diagnostics (Switzerland) on automatic analyzer Cobas 6000 (e 601 module).

The content of blood glucose was determined by oxidase method, the level of HbAlc immunoturbidity method, cholesterol and his fractions were defined by enzymatic-spectrophotometric method. Quantitative determination of immunoreactive insulin in the serum of venous blood was carried out with the help of analyzer Cobas 6000 (e 601 module) using test-system Roche Diagnostics (Switzerland), based on electro-chemiluminescence immunoassay (ECLIA). For the determi- 
nation the C-peptide a two-step immune-chemiluminescence analysis (CLIA) using the analyzer Liaison and test strips to DiaSorin (Italy) was applied.

Statistical analysis was performed on the PC using Microsoft Excel (USA) and STATISTICA 6.0. ("Statsoft", USA) software [17].

The study was performed using variational statistics and statistical coefficients. The assessment of normal distribution of index changes has been done using the Shapiro-Wilk test. The results are represented by arithmetic mean $(M)$, its standard errors $(\sigma)$ for absolute values, and the average error $(\mathrm{m})$ for relative values.

The correlation analysis was performed for all the studied indices. The r-value (linear correlation coefficient) (r) and its probabiity (p) have been measured and shown in tables.

$\mathrm{R}$-value was estimated as probable in the case when $\mathrm{p}<0.05$. While using $\mathrm{r}$-value (r) we can also observe the direction of correlation (direct + , inverse - ) and the strength of correlation (0-1). When $\mathrm{r}=0$, there is considered as no correlation, $0-0.3$ indicates low correlation, $0.3-0.7$ shows association of medium strength, $0.7-1.0$ represents strong correlation. The Pearson's correlation method is regarded as the most accurate method of studying correlation. The probable deviation or relationship between groups was represented by statistically significant coefficient $(\mathrm{p}<0.05)$.

While conducting the clinical trial we followed issues highlighted in The Helsinki Declaration of Human Rights, The European Convention on Human Rights and Biomedicine, and relevant laws of Ukraine and focused on patients' health safety, protection of patients' rights, human dignity, as well as moral and ethical standards.

\section{Results}

We could observe few correlations in patients with Graves' disease, who were involved in the study. Such interactions as TSH $-\mathrm{FT}_{4}(\mathrm{r}=-0,844 ; \mathrm{p}<0,001), \mathrm{TSH}-\mathrm{FT}_{3}(\mathrm{r}=-0,655 ; \mathrm{p}<0,001)$, $\mathrm{FT}_{4}-\mathrm{FT}_{3}(\mathrm{r}=0,600 ; \mathrm{p}<0,001)$, fasting glucose $-\mathrm{HbAlc}(\mathrm{r}=0,704 ; \mathrm{p}<0,001)$, insulinglucose HbA1cHOMA-IR ( $r=0,971 ; p<0,001)$, insulin - HOMA- $\beta(r=0,736 ; p<0,001)$ were likely to happen.

Correlation data analysis in patients with Graves' disease found out a few low- and medium-strenght correlations of lipid metabolism (Table 1). The following fact has been noticed: TSH directly correlated with LDL $(\mathrm{r}=0,201)$, on the contrary FT4 inversely correlated with the free cholesterol $(\mathrm{r}=-0,267)$, LDL $(\mathrm{r}=-0,241)$, and HDL $(\mathrm{r}=-0,209)$. Free T3 negatively correlated with HDL $(r=-0,254)$ and did not show any other probable correlations.

Table 1

Correlation relationships between TSH, FT4, FT3 and lipid profile indices in patients with Graves' disease

\begin{tabular}{cccc}
\hline Index & & Correlation & FT3 \\
\hline Total Cholesterol & TSH & FT4 & $\mathrm{r}=-0,184$ \\
HDL & $\mathrm{r}=0,233$ & $\mathrm{r}=-0,267^{*}$ & $\mathrm{r}=-0,254^{*}$ \\
LDL & $\mathrm{r}=0,165$ & $\mathrm{r}=-0,209$ & $\mathrm{r}=-0,138$ \\
VLDL & $\mathrm{r}=0,201^{\#}$ & $\mathrm{r}=-0,241^{*}$ & $\mathrm{r}=-0,143$ \\
TG & $\mathrm{r}=0,175$ & $\mathrm{r}=-0,124$ & $\mathrm{r}=0,081$
\end{tabular}

Note: * probable mean error $(p<0,05)$; \#-tendency to probable mean errors $(0,05<p<0,1)$

Specifics of correlations in carbohydrate metabolism is demonstrated in Table 2. Fasting glucose directly correlated with HbAlc $(r=0,704)$, HOMA-IR $(r=0,522)$, insulin $(r=0,322)$ and inversely correlated with HDL $(\mathrm{r}=-0,203)$. So, HbA1c also directly correlated with glucose $(\mathrm{r}=0,704)$, HOMA-IR $(r=0,460)$ and inversely correlated with the free cholesterol $(r=-0,202)$, HDL $(r=-0,257)$. The insulin level directly correlated with FT4 $(r=0,211)$, FT3 $(r=0,277)$, glucose $(r=0,322)$, HbA1c $(\mathrm{r}=0,338)$ and inversely correlated with HDL $(\mathrm{r}=-0,309)$. While determining the correlations between indices, we noted low direct correlation between $\mathrm{C}$-peptide and TG $(\mathrm{r}=0,234, \mathrm{p}<0,05)$, that had never been noticed before. 
Table 2

Correlation relationships in patients with Graves' disease

\begin{tabular}{|c|c|c|c|c|}
\hline \multirow{2}{*}{ Index } & \multicolumn{4}{|c|}{ Correlation } \\
\hline & Glucose & HbA1c & C-peptide & Insulin \\
\hline ТТГ & $\mathrm{r}=0,035$ & $\mathrm{r}=-0,063$ & $\mathrm{r}=-0,122$ & $\mathrm{r}=-0,172$ \\
\hline FT4 & $\mathrm{r}=0,075$ & $\mathrm{r}=0,184$ & $\mathrm{r}=0,123$ & $\mathrm{r}=0,211^{\#}$ \\
\hline FT3 & $\mathrm{r}=0,084$ & $\mathrm{r}=0,139$ & $\mathrm{r}=0,042$ & $\mathrm{r}=0,277^{*}$ \\
\hline Glucose & & $\mathrm{r}=0,704^{*}$ & $\mathrm{r}=-0,007$ & $\mathrm{r}=0,322 *$ \\
\hline HbAlc & $\mathrm{r}=0,704^{*}$ & & $\mathrm{r}=0,132$ & $\mathrm{r}=0,338^{*}$ \\
\hline C-peptide & $\mathrm{r}=-0,007$ & $\mathrm{r}=0,132$ & & $\mathrm{r}=-0,109$ \\
\hline Insulin & $\mathrm{r}=0,322 *$ & $\mathrm{r}=0,338$ & $\mathrm{r}=-0,109$ & \\
\hline Total Cholesterol & $\mathrm{r}=-0,096$ & $\mathrm{r}=-0,202^{\#}$ & $\mathrm{r}=0,147$ & $\mathrm{r}=-0,122$ \\
\hline HDL & $\mathrm{r}=-0,203^{\#}$ & $\mathrm{r}=-0,257^{*}$ & $\mathrm{r}=0,082$ & $\mathrm{r}=-0,309^{*}$ \\
\hline LDL & $\mathrm{r}=-0,085$ & $\mathrm{r}=-0,156$ & $\mathrm{r}=0,142$ & $\mathrm{r}=-0,065$ \\
\hline VLDL & $\mathrm{r}=0,047$ & $\mathrm{r}=-0,147$ & $\mathrm{r}=0,049$ & $\mathrm{r}=-0,116$ \\
\hline TG & $\mathrm{r}=-0,003$ & $\mathrm{r}=0,184$ & $\mathrm{r}=0,234^{*}$ & $\mathrm{r}=0,159$ \\
\hline
\end{tabular}

Note: * probable mean error $(p<0,05)$. \#-tendency to probable mean errors $(0,05<p<0,1)$

Table 3 demonstrates correlations of two IR indices: HOMA-IR and HOMA- $\beta$. Besides mentioned correlations HOMA-IR-HbA1c, HOMA-IR - glucose we can also observe direct correlations of HOMA-IR index with вT4 $(r=0,22)$, вT3 $(r=0,267)$, insulin $(r=0,971)$ and inverse correlation HDL $(r=-0,321)$. These observations correspond to other studies, which found out that HOMA-IR index and insulin positively correlate with вT3 і вT4 in patients with Graves' disease [18]. We obtained the direct correlation between HOMA- $\beta$ index and insulin $(r=0,736)$ and inverse correlation with glucose $(\mathrm{r}=-0,36)$. We were the first to note the inverse association between HOMA-IR indices and Caro index $(\mathrm{r}=-0,764)$. We consider this correlation to be logical as decreased Caro index defines hyperinsulinemia, which causes the increase of IR by HOMA-IR data and is associated with $\beta$-cells function defects.

Table 3

Correlation relationships between HOMA-IR and HOMA- $\beta$ indices in patients with Graves' disease

\begin{tabular}{ccc}
\hline Index & & Correlation \\
& HOMA-IR & HOMA- $\beta$ \\
\hline FT4 & $\mathrm{r}=0,22^{*}$ & $\mathrm{r}=0,123$ \\
FT3 & $\mathrm{r}=0,267^{*}$ & $\mathrm{r}=0,183$ \\
HbAlc & $\mathrm{r}=0,460^{*}$ & $\mathrm{r}=-0,139$ \\
Glucose & $\mathrm{r}=0,522^{*}$ & $\mathrm{r}=-0,36^{*}$ \\
Insulin & $\mathrm{r}=0,971^{*}$ & $\mathrm{r}=0,736^{*}$ \\
Caro index & $\mathrm{r}=-0,764^{*}$ & $\mathrm{r}=-0,817$ \\
HDL & $\mathrm{r}=-0,321^{*}$ & $\mathrm{r}=-0,181$
\end{tabular}

Note: *-probable mean error $(p<0,05)$. \#-tendency to probable mean errors $(0,05<p<0,1)$ 


\section{Discussion}

The results of the research found out that free thyroid hormones and thyroid-stimulating hormone (TSH) are closely related to lipid metabolism. Thus, TSH was characterized as having direct correlation with low-density lipoproteins, while the free thyroxine inversely correlated with total cholesterol, low-density lipoproteins and high-density lipoproteins, and free triiodothyronine negatively correlated with high-density lipoproteins. Our observations coincide with the research by Demellawy E. I. et al., which was based on studying the relationship between lipid metabolism and insulin sensitivity in hyperthyroidism and demonstrated the positive correlation between HDL, LDL levels, HOMA-IR indices and thyroid hormones (FT3 i FT4) [19].

Fasting glucose directly correlated with HbAlc, HOMA-IR, insulin and inversely correlated with HDL. Unidirectional correlations between HbAlc and blood glucose $(p<0,05)$ have been found out. It means that $\mathrm{HbAlc}$ is a summary index of the average glucose level over the previous 2-3 months. So, HbAlc also directly correlated with glucose, HOMA-IR and inversely correlated with the free cholesterol, HDL. The insulin level directly correlated with FT4, FT3, glucose, HbA1c, and inversely correlated with HDL. Described observations prove the opinions of other authors, who found out the positive correlation between insulin and вT4 in patients with Graves' disease [20].

The further scientific researches will be focused on the study of clinical and pathogenetic correlation between IR indices and Graves' disease, as well as on the ways of IR correction in thyroid disorders.

\section{Conclusions}

The research determined that the insulin level is directly correlated with free thyroxine and free triiodothyronine in patients with Graves' disease. HbA1c directly correlated with HOMA-IR index and inversely correlated with HOMA- $\beta$. HOMA-IR index and Caro index correlated inversely.

While determining the correlations between indices, we noted low direct correlation between C-peptide and triglycerides that had not been noticed before.

The study proves the presence of insulin resistance in patients with Graves' disease that generates interest to further study of the changes in insulin sensitivity, relation of insulin resistance to thyroid-stimulating hormone, thyroid hormones and looking for the ways to correct these disorders.

\section{References}

[1] Biondi, B., Kahaly, G. J. (2010). Cardiovascular involvement in patients with different causes of hyperthyroidism. Nature Reviews Endocrinology, 6 (8), 431-443. doi: 10.1038/nrendo.2010.105

[2] Dimitriadis, G., Hatziagelaki, E., Mitrou, P., Lambadiari, V., Maratou, E., Raptis, A. E. et. al. (2011). Effect of Hyperthyroidism on Clearance and Secretion of Glucagon in Man. Experimental and Clinical Endocrinology \& Diabetes, 119 (04), 214-217. doi: 10.1055/s-0030-1269880

[3] Pankiv, V. I. (2013). The relationship between the pathology of the thyroid gland and type 2 diabetes. Health of Ukraine, 2, 36-37.

[4] Raboudi, N., Arem, R., Jones, R. H. et. al. (1989). Fasting and postabsorptive hepatic glucose and insulin metabolism in hyperthyroidism. Journal of Physiology Endocrinology and Metabolism, 256, 159-166.

[5] Brandt, F., Thvilum, M., Almind, D., Christensen, K., Green, A., Hegedus, L., Brix, T. H. (2013). Hyperthyroidism and psychiatric morbidity: evidence from a Danish nationwide register study. European Journal of Endocrinology, 170 (2), 341-348. doi: 10.1530/eje-13-0708

[6] Kapadia, K. B., Bhatt, P. A., Shah, J. S. (2012). Association between altered thyroid state and insulin resistance. Journal of Pharmacology and Pharmacotherapeutics, 3, 156-160.

[7] Lishchuk, O. Z., Kikhtyak, O. P., Moskva, H. A., Lishchuk, B. F. (2014). Changes in sensitivity to insulin in the pathogenesis of diffuse toxic goiter. Clinical endocrinology and endocrine surgery, 1 (46), 77-82.

[8] Brenta, G. (2011). Why Can Insulin Resistance Be a Natural Consequence of Thyroid Dysfunction? Journal of Thyroid Research, 2011, 1-9. doi: 10.4061/2011/152850

[9] Paul, D. T., Mollah, F. H., Alam, M. K. et. al. (2004). Glycemic status in hyperthyroid subjects. Mymensingh Medical Journal, 13 (1), 71-75. 
[10] Bloomgarden, Z. T. (2011). World Congress on Insulin Resistance, Diabetes, and Cardiovascular Disease: Part 4. Diabetes Care, 34 (10), e152-e157. doi: 10.2337/dc11-1306

[11] Chidakel, A., Mentuccia, D., Celi, F. S. (2005). Peripheral Metabolism of Thyroid Hormone and Glucose Homeostasis. Thyroid, 15 (8), 899-903. doi: 10.1089/thy.2005.15.899

[12] Ortega, E., Koska, J., Pannacciulli, N., Bunt, J. C., Krakoff, J. (2008). Free triiodothyronine plasma concentrations are positively associated with insulin secretion in euthyroid individuals. European Journal of Endocrinology, 158 (2), 217-221. doi: 10.1530/eje-07-0592

[13] Feng, X. (2000). Thyroid Hormone Regulation of Hepatic Genes in Vivo Detected by Complementary DNA Microarray. Molecular Endocrinology, 14 (7), 947-955. doi: 10.1210/me.14.7.947

[14] Garduno-Garcia, J. D. J., Alvirde-Garcia, U., Lopez-Carrasco, G., Padilla Mendoza, M. E., Mehta, R., Arellano-Campos, O. et. al. (2010). TSH and free thyroxine concentrations are associated with differing metabolic markers in euthyroid subjects. European Journal of Endocrinology, 163 (2), 273-278. doi: 10.1530/eje-10-0312

[15] Antonelli, A., Fallahi, P., Ferrari, S. M. et. al. (2011). 3,5-diiodo-L-thyronine increases resting metabolic rate and reduces body weight without undesirable side effects. Journal of Biological Regulators \& Homeostatic Agents, 25 (4), 655-660.

[16] Lishchuk, O. Z., Kikhtyak, O. P., Moskva, H. A. (2016). The analysis of results of PPAR- $\gamma$ agonist pioglitazone using in patients with diffuse toxic goiter and insulin resistance. East European Scientific Journal, 10 (2), 40-43.

[17] Borovikov, V. (2001). Statistica: the art of analysis on PC. For professionals. Vol. 1. Saint Petersburg: Piter, 656.

[18] Purohit, P. (2012). Estimation of serum insulin, Homeostasis model assessment-insulin resistance and C-peptide can help identify possible cardiovascular disease risk in thyroid disorder patients. Indian Journal of Endocrinology and Metabolism, 16 (7), 97-103. doi: 10.4103/2230-8210.94263

[19] Dimitriadis, G., Maratou, E., Boutati, E., Kollias, A., Tsegka, K., Alevizaki, M. et. al. (2008). IGF-I increases the recruitment of GLUT4 and GLUT3 glucose transporters on cell surface in hyperthyroidism. European Journal of Endocrinology, 158 (3), 361-366. doi: 10.1530/eje-07-0532

[20] Pavliuk, P. M. (1990). Disordered glucose tolerance in diffuse toxic goiter. Endocrinology problems, 36 (2), 17-21. 